\title{
Akne Klinik
}

\section{Prof. Dr. Ayten Ferahbaș Kesikoğlu}

Demiroğlu Bilim Üniversitesi Tıp Fakültesi, Deri ve Zührevi Hastalıklar Anabilim Dalı, İstanbul, Türkiye

\section{Öz}

Akne klinik belirtileri polimorfik özellikte olup lezyonlar, primer ve sekonder olmak üzere iki grupta incelenebilir. Primer akne lezyonları, açık ve kapalı komedonlar, papül, püstül ve nodüllerdir. Sekonder lezyonlar ise çoğu kez primer lezyonlardan gelişen apse, kist, post-enflamatuvar hiperpigmentasyon, ekskoriasyon izleri ve skarlardan oluşur. Hastalığın aktivitesini primer lezyonların şiddeti belirler.

Anahtar Kelimeler: Komedon, Papül, Püstül

\section{Abstract}

The clinical symptoms of acne are of polymorphic nature and its lesions can be investigated in two groups, primary and secondary. The primary acne lesions include open and closed plugged pores, papules, pustules, and nodules. Developing mostly from primary lesions, the secondary lesions include abscesses, cysts, post-inflammatory hyperpigmentation, signs of excoriation, and scars. The severity of primary lesions determines the disease activity.

Keywords: Comedone, papule, pustule

\section{Akne vulgaris}

Akne vulgaris (AV) tüm akne olgularının \%99'unu oluşturan, en çok yüz, boyun, göğüs, üst sırt ve üst kollar dahil olmak üzere vücudun hormonal olarak duyarlı yağ bezlerine sahip bölgelerini etkileyen, kronik, enflamatuvar bir hastalıktır ${ }^{1,2}$. $A V^{\prime}$ de lezyonlar en sık yüzde bulunur ${ }^{3,4}$. Ülkemizden yapılan 3.837 hastanın incelendiği epidemiyolojik bir çalışmada, hastaların tamamının yüzünde AV lezyonları bulunmuştur. Bu çalışmada hastaların \%56,4'ünde sırtta ve \%28'inde göğüs bölgesinde lezyonların yerleştiği bildirilmiştir. Kadın hastalarda yüz yerleşimli, erkek hastalarda ise sırt yerleşimli akne daha sık bulunmuştur ${ }^{5}$.

\section{Akne lezyon tipleri}

AV'nin klinik belirtileri polimorfik olup primer akne lezyonları, açık ve kapalı komedonlar, papül, püstül ve nodüller; sekonder lezyonlar ise apse, kist, post-enflamatuvar hiperpigmentasyon, ekskoriyasyon izleri ve skarlardan oluşur. Hastalığın aktivitesini primer lezyonların şiddeti belirler 6 .

\section{A. Primer akne lezyonları}

Primer akne lezyonları enflamatuvar ve non-enflamatuvar lezyonlar olmak üzere iki grupta toplanabilir.

\section{Non-enflamatuvar lezyonlar}

Genç hastalarda en erken belirti olarak ortaya çıkan komedonlardır. Mikrokomedonlar AV'nin klinik lezyonlarının öncüsü olarak kabul edilir².

a) Kapalı komedonlar: Sebase bezin kanalının açıldığı kıl folikülünün açıklığının sebum ve keratinositlerle tıkanması ile ortaya çıkarlar. Genellikle $1 \mathrm{~mm}$ çaplı, deri renginde, küçük,

Yazışma Adresi/Address for Correspondence: Prof. Dr. Ayten Ferahbaş Kesikoğlu

Demiroğlu Bilim Üniversitesi Tip Fakültesi, Deri ve Zührevi Hastalıklar Anabilim Dall, İstanbul, Türkiye

E-posta: aytenferahbaskesikoglu@gmail.com ORCID: orcid.org/0000-0002-8121-2093

(c) Telif Hakkı 2020 Deri ve Zührevi Hastalılar Derneği

Türkderm - Türk Deri Hastalıkları ve Frengi Arșivi, Galenos Yayınevi tarafından basılmıștır. 
kubbe şeklinde ve genellikle kolay fark edilmeyen lezyonlardır. Kapalı komedonların tespit edilmesi için; iyi bir aydınlatma, muayene alanındaki derinin gerilmesi ve palpasyon gerekir. En sık yerleştiği bölgeler burun üzeri, alın ve yanakların üst kısımlarıdır 2,4,7 (Resim 1).

b) Açık komedonlar: Ortalarında gözle görülür dilate folikül açıklıkları bulunan kubbe şeklinde papüllerdir. Yoğun şekilde sıkışmıs keratinositler, oksitlenmiş lipitler ve melanin, hepsi açık komedonun koyu rengine katkıda bulunur. Erken başlaması kötü prognoz göstergesidir (Resim 2). Ekstrakte edildiğinde yaklaşık 2-6 hafta sonra yeniden dolar ${ }^{2,8}$.

Klinik davranışları, büyüklükleri ve morfolojilerine göre komedonların birçok farklı tipi tanımlanmıştır.

- Kayıp komedonlar: Görülebilmesi için deriyi gerginleştirmek ve sığ bir açı ile iyi bir ışık kullanmak gereken komedonlar.

- Makrokomedonlar: Çapı 1 mm'den büyük, beyaz papüller.

- Deniz altı komedonlar: 0,5 cm'den büyük, deride daha derin yerleşimli, geniş komedonlar gibi alt tipleri vardır ${ }^{1,4,9}$.

\section{Enflamatuvar lezyonlar}

AV'nin enflamatuvar lezyonları, papül (Resim 3), püstül (Resim 3) ve nodüllerdir (Resim 4). Non-enflamatuvar lezyonlardan ya da mikrokomedonlardan oluşur, özellikle yüz ve/veya sırtta daha yoğun bulunurlar. Foliküler rüptür, enflamatuvar lezyonların gelişmesine katkıda bulunur. Foliküler rüptürü takiben pro-enflamatuvar lipidler ve keratin, çevre dermise ekstraksiyon yoluyla iltihaplı papül veya nodül

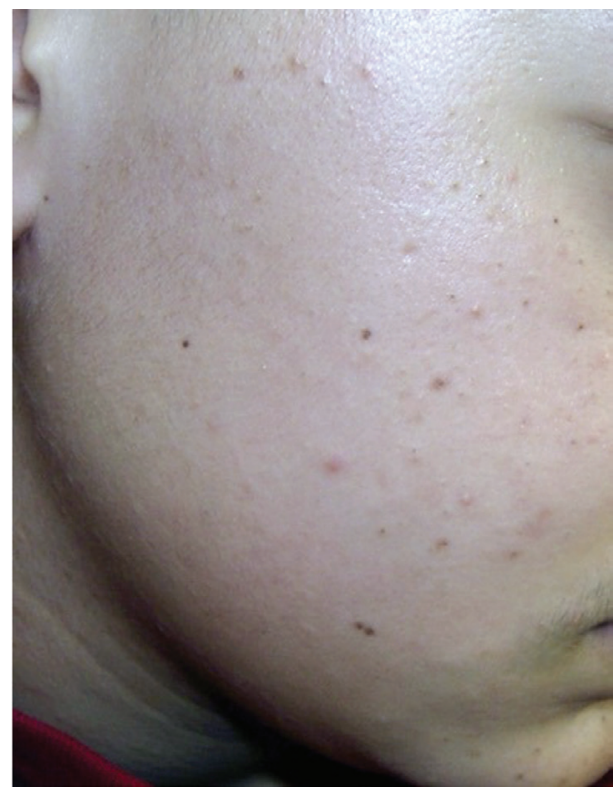

Resim 1. Yanakta kapalı (beyaz) ve az sayıda açık (siyah) komedonlar

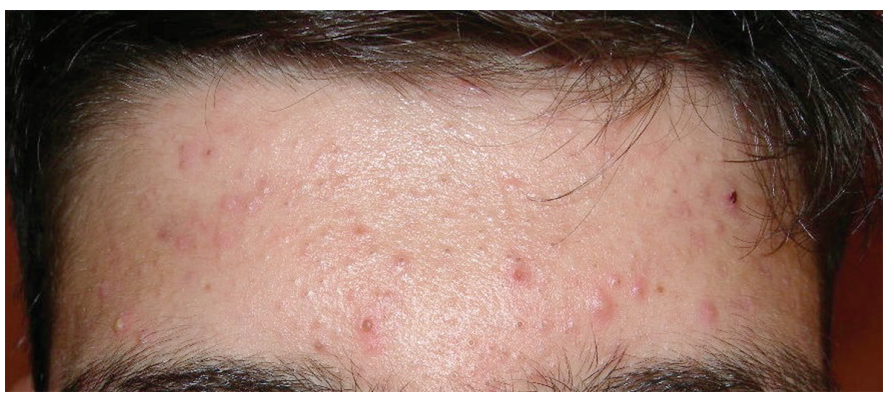

Resim 2. Yüz frontal bölgede açık komedonlar ve az sayıda papüller oluşumuna neden olur ${ }^{1,2,10}$. Nodüller veya derin püstüller arasındaki sinüs traktları skarlara neden olur. Bu lezyonlar oldukça ağrılı, kronikleşmeye meyilli ve tedaviye dirençlidir ${ }^{1,2,4}$.

Enflamatuvar maküller lezyonların gerilemesinden sonra kalan ve birkaç hafta/ay devam edebilen eritematöz, gerilemiş lezyonlardır2,4.

\section{B. Akne vulgaris'in sekonder lezyonları}

1. Kistler: Büyük, içi püy dolu, genellikle deride daha derin yerleşimli lezyonlar olup çok inflame ve ağrılıdır. Kistler, genellikle bir komedon içeriğinin, çevreleyen deriye dağılması ve ortaya çıkan immün reaksiyon sonucunda oluşur. Gerçekte, tam kistler nadirdir. Flüktüasyon veren lineer lezyonlar olarak görülen sinüs izleri, nodüllerin birleşmesiyle oluşur (Resim 4, 5). İyileşirken genellikle skar bırakırlar ${ }^{1,2}$.

2. Skarlar: Aknenin en yaygın komplikasyonudur ve hasta uygun tedaviyi aldığı halde bile ortaya çıkabilmektedir. Akne skarlarının kozmetik görünümü bozmasının yanı sıra depresyon, ruhsal problemler, intihar düşüncesi ve genel sosyal bozukluklara neden olabilmektedir ${ }^{11,12}$. Akne skarları atrofik skarlar (Resim 6) [boxcar (yük vagonu), ice pick (buz kıracağı) ve rolling] $]^{1,11,12}$ ve hipertrofik skarlar ve keloid (Resim 7) olarak

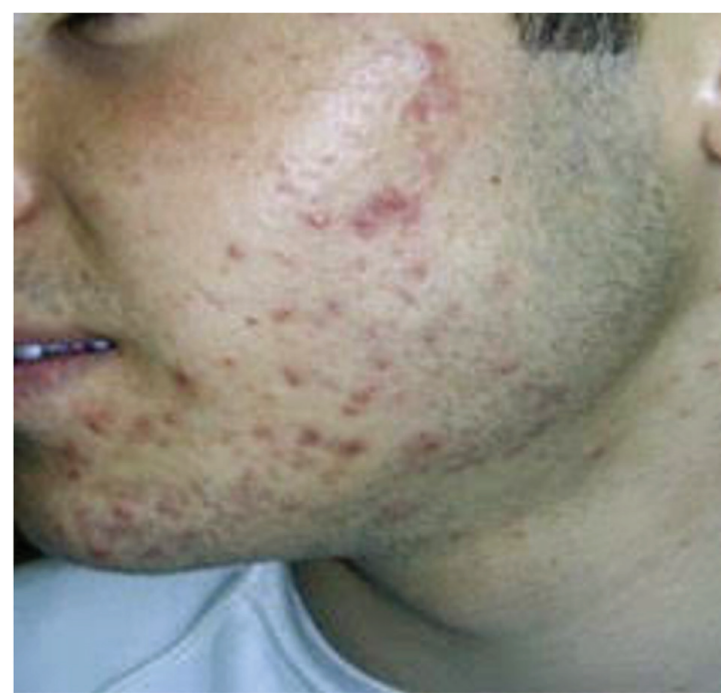

Resim 3. Yanakta papül ve püstüller

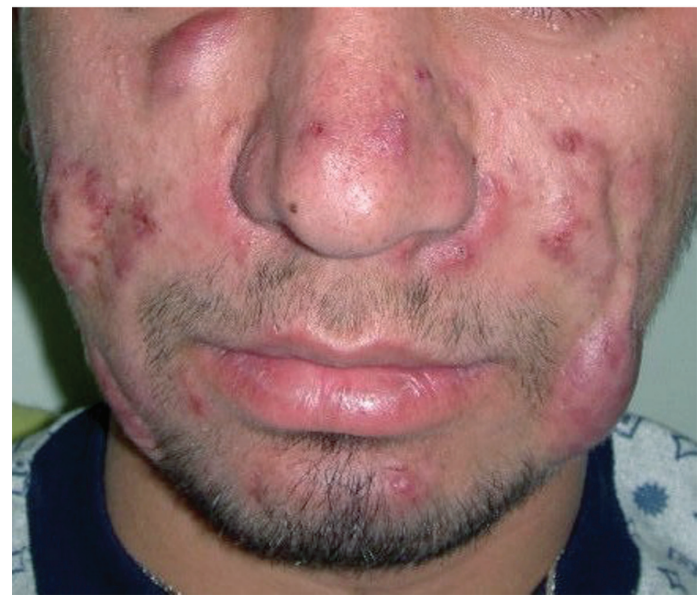

Resim 4. Nodüller 
iki ana gruba ayrilır1,11,12. Post-enflamatuvar hiperpigmentasyon (PIHP) AV'nin en sık komplikasyonlarından biri olup deri rengi koyulaştıkça PIHP görülme riski artmaktadır ${ }^{13-15}$. AV lezyonları bazen kaşıntılı olabilir. Kaşıntının Propionibacterium acnes tarafından salgılanan histamin benzeri bileşikler tarafından oluşturulduğu tahmin edilmektedir ${ }^{16}$.

\section{Akne fulminans}

Akne fulminans ciddi skarlarla sonlanan akut başlangıçlı şiddetli bir akne türü olup tüm akne hastalarının \%1'ini oluşturur. Lezyonlar ağrılı, yaygın papüller, plaklar, hemorajik nodüller ve nekrotik zeminli ülserasyonların görülmesi ile karakterizedir ${ }^{17-19}$ (Resim 8).

Yerleşim yeri sıklıkla yüz, gövde ve sırt olup nadiren uyluklarda da görülebilir20. Genellikle hafif ya da orta şiddetli AV tanısı olan 13-22 yaşlarındaki adölesan erkek hastalarda ortaya çıkar. Hastaların çoğunda deri lezyonlarına sistemik semptomlar ve bulgular eşlik eder. En sık eşlik eden sistemik bulgular ateş, miyalji ve artraljidir. Bunlara ek olarak eritema

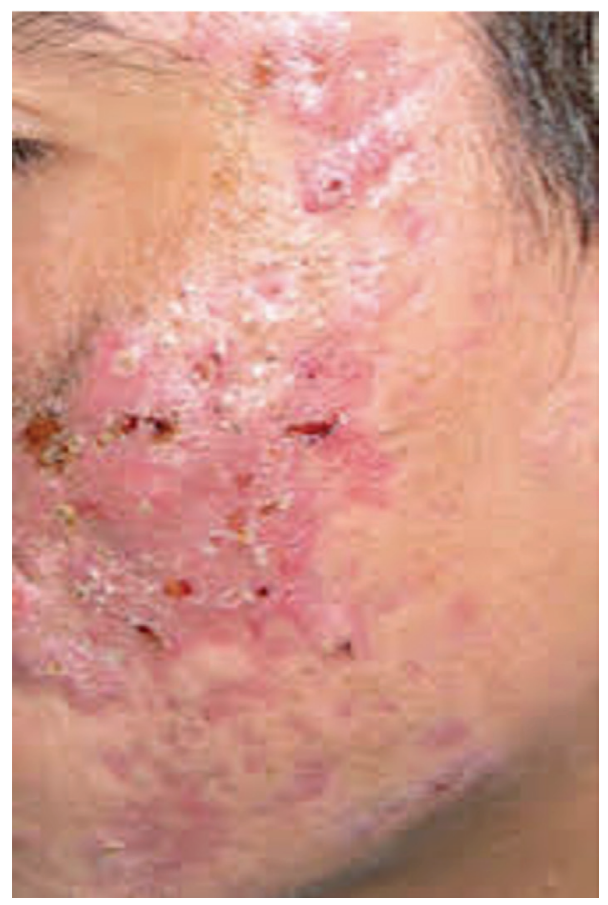

Resim 5. Nodül ve sinüsler

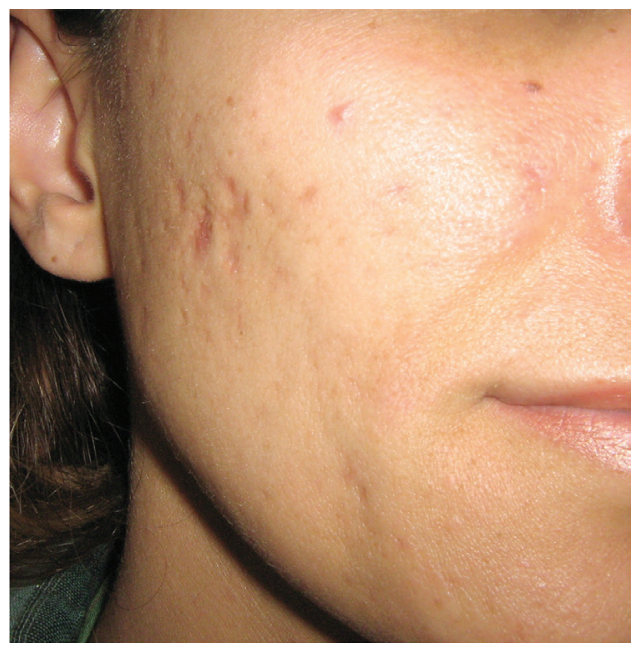

Resim 6. Deprese skar nodozum, hepatosplenomegali, miyozit, anoreksi, kilo kaybı ya da aseptik osteomiyelit benzeri osteolitik kemik lezyonları da eşlik edebilir. Osteomiyelit benzeri osteolitik lezyonlar hastalıktaki en sık kemik lezyonlarıdır ve genellikle sternum ve sternoklavikular eklemlerde görülür. Bu lezyonlar sterildir ve iyi prognozludur. Hastaların \%21'inde ise sakroileit görülür. Bu durum hastanın yürümesini engelleyecek ve hatta tekerlekli sandalye kullanmayı gerektirecek kadar şiddetli olabilir, karakteristik olarak ağrılı, öne doğru eğik olarak yürürler ${ }^{17}$.

Akne fulminans tek başına görülebildiği gibi sinovit, akne, püstüloz, hiperostoz ve osteit (SAPHO), piyojenik artrit, piyoderma gangrenozum ve akne (PAPA), piyoderma gangrenozum, akne, süpüratif hidradenit (PASH) ve piyojenik artrit, piyoderma gangrenozum, akne, süpüratif hidradenit (PAPASH) gibi çeşitli sendromların bir bileşeni olarak da görülebilir (Tablo 1).

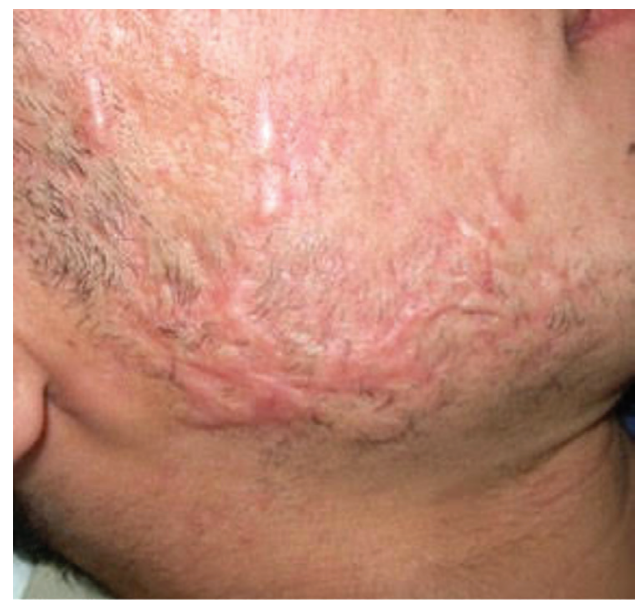

Resim 7. Hipertrofik skar

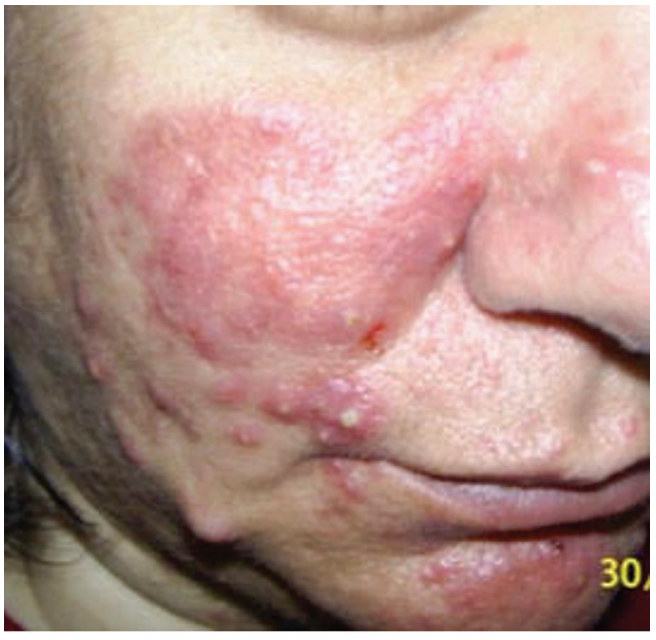

Resim 8. Akne fulminans

\section{Tablo 1. Akneye eşlik eden sendromlar ${ }^{21,22}$}

SAPHO sendromu: Sinovit, akne, püstülozis, hiperostozis ve osteitis

PAPA sendromu: Piyojenik artrit, piyoderma gangrenozum ve akne

PASH sendromu Piyoderma gangrenozum, akne, Hidradenitis süpürativa

PAPASH sendromu Piyoderma gangrenozum, akne, Hidradenitis süpürativa ve piyojenik artrit 


\section{Akne konglobata}

Akne konglobata en sık erişkin erkeklerde görülen sistemik bulguların olmadığı veya az olduğu nadir görülen fakat şiddetli bir akne formudur. Lezyonlar gövde ve üst ekstremitelerde görülmekte ve genellikle gluteal bölgeye kadar uzanmaktadır. AV'nin aksine, yüz lezyonları yaygın değildir ${ }^{23,24}$. Akne konglobata çok sayıda enflamatuvar papül, ağrılı nodüller ve genellikle drene olan sinüsleri oluşturmak için birleşen apseler, çok sayıda gruplaşmış komedonlar ve yaygın şekil bozukluğuna neden olan skarlar ile karakterizedir. Akne konglobata, hidradenitis süpürativa ve saçlı derinin dissekan selülitinin varlığında foliküler oklüzyon triadını oluşturmakta bunlara pilonidal sinüs eklendiğinde ise foliküler oklüzyon tetradını oluşturmaktadır. SAPHO, PAPA, PASH ve PAPASH gibi sendromların bir parçası olarak da görülebilmektedir. Tedavisi son derecede zordur ${ }^{23,25}$.

\section{Akne tarda}

Erişkinde 25 yaş üzeri bireylerde görülen akne; erişkin başlangıçlı akne, akne tarda veya post-pubertal akne gibi isimlerle anılmaktadır. Akne tardaya kadınlarda erkeklere kıyasla daha sık rastlanı ${ }^{26-31}$.

\section{Akne tarda 3 gruba ayrılır;}

Persistan akne: Adölesan dönemde başlayıp erişkinlikte devam eden akne tarda formudur.

Geç-akne: Yetişkin çağda başlayan akne formudur.

Rekürren akne tarda: Adölesan dönemde başlangıç gösteren ancak değişken sürelerle aknesiz bir dönem geçirildikten sonra erişkin yaşta akne probleminin tekrar başladığı hastalardır ${ }^{32}$.

Akne tarda adölesan dönemden farklı klinik özellikler gösterir. Ağırlıklı olarak papül ve püstüller mevcuttur, komedonlar nadir görülür veya yoktur. Genellikle hafif veya orta şiddette seyreder ve genellikle yüzün U-bölgesi de denilen çene, yanak ve mandibular bölgede yerleşmektedir ${ }^{32}$. Ancak, nodül ve kistlerle seyreden daha şiddetli formlarına erkek hastalarda daha sık rastlanmaktadır ${ }^{33}$. Klinikte kadın hastalarda enflamatuvar lezyonlar dışında, yer yer komedonlar, derin ve ağrısız nodüller, bu nodüllere sekonder gelişen post-enflamatuvar hiperpigmentasyon izlenebilir. Gövde aknesi daha az görülür, yaklaşık \%70'inde hipersebore vardır. Menstrüasyon öncesi daha sık görülür ${ }^{13}$. Bu alevlenmeler menstrüal siklusun son haftasında foliküler duvarın artan su içeriğinden kaynaklanmaktadır ve androjenik, progesteron türevi oral kontraseptif kullanan hastalarda (birinci ve ikinci nesil) daha yeni formülasyonlar kullanan hastalara göre daha belirgindir. Kalıcı, nükseden ve yeni başlayan yetişkin kadın akne tipleri sıklıkla enflamasyon (derin nodüller), enflamasyon sonrası pigmentasyon ve yüksek skar sıklığı ile ilişkilidir. Her ne kadar akne tardası olan her hastada endokrinolojik anormalliklerin bulunması mutlak olmasa da hirsutizm ve düzensiz menstrüal periyodları olan kadın hastalarda hiperadrojenizmden şüphenilmelidir ${ }^{33}$.

Diğer akne varyantları: Klinik olarak kozmetik akne, deterjan aknesi, mekanik akne, akne ekskoriye, mesleki akne, klor aknesi, radyasyon aknesi, akne estivalis (mallorka aknesi) gibi çeşitli akne varyantları bulunmaktadır ${ }^{34.42}$.

\section{Kozmetik akne}

Komedojenik madde içeren çeşitli kozmetik ürünlerin uzun süre kullanımı sonucu gelişen, uniform görünümlü çoğunlukla kapalı bazen de açık komedonlarla, nadiren de püstüllerle karakterizedir. Neden olan kozmetik ürünün kesilmesi ile tablo yavaşça gerilemektedir ${ }^{34,35}$.

\section{Deterjan aknesi}

Deterjan aknesi alkali sabunlarla aşırı yıkama ve ovalama sonucu ortaya çıkan papül ve püstüllerle karakterize nadir bir akne varyantıdır. Alkali temizleyicilerle yıkama sonucu deri kuruluğu artmakta ve deri mikroflorasında değişiklik görülmektedir ${ }^{34,36,37}$.

\section{Mekanik akne}

Kemer gibi giysilerin sıkı olduğu alanlarda, mesleki nedenli olarak uzun süre oturan, örneğin; kamyon şoförlerinin sırt ve kalçalarında, diş tedavisi sonrası perioral alanda, kask, dizlik gibi koruyucu giysi kullanan sporcularda veya uzun süre yatan kişilerin sırt, omuz gibi bası alanlarında görülmektedir. Ayrıca yüze bakım ve güzellik amacıyla uygulanan bazı işlemlerin de mekanik akneye yol açtığını bildiren çalışmalar bulunmaktadır ${ }^{17}$. Folikül yapısındaki bozulmanın veya kozmetik ürünleri sürmek için yüze uygulanan kuvvetli friksiyonun epidermal hasara neden olarak şiddetli enflamasyona yol açtığı ileri sürülmüştür ${ }^{34,39}$.

\section{Akne ekskoriye}

Anksiyete, depresyon, obsesif kompulsif bozukluk, vücut dismorfik bozukluğu, parazit delüsyonları veya kişilik bozuklukları sonucu oluşabilen bu tablo çoğunlukla ergen kızlarda veya genç kadınlarda görülmektedir. Hastaların komedonları veya enflamatuvar papülleri sürekli sıkmaları, koparmaları veya delmeleri sonucunda lezyonların üzerinde skar bırakabilen krutlu erozyon gelişmektedir.

\section{Meslek aknesi}

Endüstriyel çözünür olmayan yağlar, kömür katranı deriveleri, klor gibi halojen kimyasallarla veya petrol kaynaklı yağlarla temas mesleki aknenin en önemli nedenleridir. İçlerinde en sık klorlu halojenlerle temasa bağlı olarak klor aknesi görülmektedir. Bu yağlı maddeler folikül ağızlarında tıkanmaya yol açarak akneyi oluşturmaktadır. Lezyonlar aknenin predileksiyon alanlarında oluşabileceği gibi kollar veya abdomen gibi beklenenin dışındaki alanlarda da gelişebilir ${ }^{34,40}$.

\section{Klor aknesi}

Klorlu polisiklik aromatik hidrokarbonlarla fabrikada üretim sırasında temas eden endüstri işçileri, tarım sektöründe çalışan işçiler, patlama sonucu oluşan kazalarda çevresel kirlenme sonucu temas eden kişiler veya kontamine yiyecekleri tüketen kişilerde temastan birkaç hafta/ay sonra ortaya çıkmaktadır. Klor aknesi dıştan temasla oluşabileceği gibi sistemik intoksikasyonla da gelişebilir.

Ayrıca göz, karaciğer ve santral sinir sistemi bulguları da görülür. Klinik olarak lezyonlar; göz çevresi, retroauriküler ve mandibular bölgeler, boyun, gluteal ve aksiller bölgeler ile skrotumda çok sayıda komedon ve zaman içinde oluşan saman sarısı epidermal kistler şeklinde görülür. Hiperpigmentasyon, hipertrikoz ve porfirya kutanea tarda da gelişebilir ${ }^{34-41}$.

\section{Radyasyon aknesi}

Radyoterapi sonrası radyasyon alanında gelişen çoğunlukla açık veya kapalı komedonlarla karakterize bir aknedir. Bu nadir görülen yan etki yüksek dozlu, derin penetrasyonlu radyoterapi alan hastalarda ortaya çıkmaktadır ${ }^{36}$. İyonize radyasyonun folikül epitelinde oluşturduğu metaplazinin yol açtığı ileri sürülmektedir ${ }^{34-42}$.

\section{Akne aestivalis (mallorka aknesi)}

Aknesi olmayan bazı kişilerde güneş ışı̆ıına maruziyetten sonra omuz, kollar, sırt ve göğüs bölgesinde çoğunlukla monomorfik papüller ve 
bazen püstüller gelişebilmektedir. Akne aestivalis olarak isimlendirilen bu akne varyantı özellikle Akdeniz gibi yoğun güneşli bölgelerde tatile giden kissilerde görülmektedir. Ayrıca psoralen ve ultraviyole A tedavisi ile gelişen olgular da bildirilmiştir $34,38,43$.

\section{Kaynaklar}

1. Emre $S$, Aktaş $A$ : Akne kliniği, akne vulgaris, akne ve rozase tanı ve tedavi. Sarıcaoğlu H, Ünal İ, Karaman G, Kesikoğlu Ferahbaş A, Karadağ AS, Aktürk Şikar A, Kalkan G, eds. İstanbul: Galenos Yayınevi; 2018;5:94-9.

2. Ramli R, Malik AS, Hani AFM, Jamil A: Acne analysis, grading and computational assessment methods: An overview. Skin Res Technol 2012;18:1-14

3. Mogaddam MR, Ardabili NS, Maleki N, Soflaee M: Correlation between the severity and type of acne lesions with serum zinc levels in patients with acne vulgaris. Biomed Res Int 2014;474108.

4. Layton AM, Eady EA, Zouboulis CC: Acne. Rook's Te tbook of dermatology. Griffiths CEM, Barker, Bleiker T, Calmers R, Creamer D. New Delhi, Wiley Blackwell, editors 9th ed. Hoboken, New Jersey: Wiley-Blackwell Publisher: 2016:90:1-66

5. Karadağ AS, Balta i, Saricaoğlu H, et al: The effect of personal, familial, and environmental characteristics on acne vulgaris: A prospective, multicenter, case controlled study from Turkey. G Ital Dermatol Venereol 2019;154:17785.

6. Becker M, Wild T, Zouboulis CC: Objective assesment of acne. Clin Dermatol 2017;35:147-55.

7. Egbers R, Do T, Voorhees JJ, et al. Computer-assisted alignment and tracking of comedones in patients with predominantly comedonal acne indicate that most resolve within 4 weeks and do not become inflammatory lesions. J Invest Dermatol 2010;130:58.

8. Saurat JH: Strategic targets in acne: The comedone switch in question. Dermatology 2015;231:105-11.

9. Cunliffe WJ, Holland DB, Clark SM, Stables GI: Comedogenesis: Some new aetiological, clinical and therapeutic strategies. Br J Dermatol 2000;142:108491.

10. Zeichner A: Inflammatory acne treatment: Review of current and new topical therapeutic options. Drugs Dermatol 2016;15:11-6.

11. Lanoue J, Goldenberg G: Acne scarring: A review of cosmetic therapies. Cutis 2015;95:276-81.

12. Rivera AE. Acne scarring: A review and current treatment modalities. J Am Acad Dermatol 2008;59:659-76.

13. França K, Keri J: Psychosocial impact of acne and postinflammatory hyperpigmentation. An Bras Dermatol 2017;92;505-9.

14. Taylor SC, Cook-Bolden F, Rahman Z, et al: Acne vulgaris in skin of color. J Am Acad Dermatol 2002;46:98-106.

15. Darji K, Varade R, West D, Armbrecht ES, Guo MA: Psychosocial impact of postinflammatory hyperpigmentation in patients with acne vulgaris. J Clin Aesthet Dermatol 2017;10:18-23.

16. Dalgard F, Halvorsen A, Kwata SG, Yosipovitch G: Acne severity and itch are associated: results from a Norwegian survey of 3775 adolescents. $\mathrm{Br} J$ Dermatol 2013;169:181-232.

17. Yalçın B: Akne Kliniği, Akne Fulminans. Akne ve rozase tanı ve tedavi. Sarıcaoğlu H, Ünal I, Karaman G, Kesikoğlu Ferahbaş A, Karadağ AS, Aktürk Şikar A, Kalkan G, editors. İstanbul: Galenos Yayınevi; 2018;5:100-4.

18. Zaba R, Schwartz R, Jarmuda S, Czarnecka-Operacz M, Silny W: Acne fulminans: Explosive systemic form of acne. J Eur Acad Dermatol Venereol 2011;25:501-7.

19. Zanelato TP, Gontijo GM, Alves CA, et al. Disabling acnefulminans. An Bras Dermatol 2011;86:9-12

20. Saint- Jean M, Frenard C, Le Bras M, et al: Testosterone-induced acne fulminans in twins with Kallmann's syndrome. J Am Acad Dermatol Case Rep 2014;1:27-9.
21. Greywal T, Zaenglein AL, Baldwin HE, et al: Evidence-based recommendations for the management of acne fulminans and its variants. J Am Acad Dermatol 2017;77:109-17.

22. Join-Lambert $O$, Duchatelet $S$, Delage $M$, et al: Remission of refractory pyoderma gangrenosum, severe acne, and hidradenitis suppurativa (PASH) syndrome using targeted antibiotic therapy in 4 patients. J Am Acad Dermatol 2015;73:66-9.

23. Türel Ermertcan, Öztürk F: Akne kliniği, akne konglobata. Akne ve rozase tanı ve tedavi. Sarıcaoğlu H, Ünal i, Karaman G, Kesikoğlu Ferahbaş A, Karadağ AS, Aktürk Şikar A, Kalkan G editors. İstanbul: Galenos Yayınevi, Türk Dermatoloji Derneği Yayınlarl; 2018:105-8.

24. Layton AM: Disorders of the sebaceous glands. rook's textbook of dermatology. Burns T, Breathnach S, Co N, Griffi C, editors 8th edition. New Delhi: Wiley AJ\& Sons; 2010;42:82-3.

25. Dessinioti C, Katsambas A: Difficult and rareforms of acne. Clin Dermatol 2017;35:138-46.

26. Yılmaz E, Bilgiç Temel A. Akne kliniği, akne tarda. Akne ve rozase tanı ve tedavi. Sarıcaoğlu H, Ünal I, Karaman G, Kesikoğlu Ferahbaş A, Karadağ AS, Aktürk Şikar A, Kalkan G, editors. İstanbul: Galenos Yayınevi; 2018;5:11520.

27. Zeichner A, Baldwin HE, Cook-Bolden FE, Eichenfield LF, Fallon-Friedlander S, Rodriguez DA: Emerging Issues in Adult Female Acne. J Clin Aesthet Dermatol 2017;10:37-46.

28. Duman $D$, Şahin S: Aknenin klinik bulguları ve tipleri. Türkiye Klinikleri Dermatol-Special Topics 2016;9:20-6.

29. Ramos-e-Silva M, Ramos-e-Silva S, Carnerio S: Acne in women. Br J Dermatol 2015;172:20-6.

30. Trivedi MK, Shinkai K, Murase E: A Review of hormone-based therapies to treat adult acne vulgaris in women. Int J Womens Dermatol 2017;3:44-52.

31. Tanghetti EA, Kawata AK, Daniels SR, Yeomans K, Burk CT, Callender VD: Understanding the burden of adult female acne. J Clin Aesthet Dermatol 2014; 7:22-30.

32. Choi C, Lee DH, Kim HS, Kim BY, Park KC, Youn SW: The clinical features of late onset acne compared with early onset acne in women. J Eur Acad Dermatol Venereol 2011;25:454-61.

33. Dreno B, Bagatin E, Blume-Peytavi U, Rocha M, Gollnick H: Female type of adult acne: Physiological and psychological considerations and management. J Dtsch Dermatol Ges 2018;16:1185-94.

34. Kıran. Akne kliniği, akne varyantları. Akne ve rozase tanı ve tedavi. Sarıcaoğlu H, Ünal I, Karaman G, Kesikoğlu Ferahbaş A, Karadağ AS, Aktürk Şikar A, Kalkan G, editors. İstanbul: Galenos Yayınevi; 2018;5:121-8.

35. Korting HC, Borelli C, Schölmann C: Acne vulgaris. Role of cosmetics. Hautarzt 2010;61:126-31.

36. Kane A, Niang SO, Diagne AC, et al. Epidemiologic, clinical, and therapeutic features of acne in Dakar, Senegal. Int J Dermatol 2007;46:36-8.

37. Solomon BA, Shalita AR: Effects of detergents on acne. Clin Dermatol 1996;14:95-9.

38. Pluetrattanabha $N$, Kulthanan $\mathrm{K}$, Nuchkull $\mathrm{P}$, Varothai $\mathrm{S}$ : The $\mathrm{pH}$ of skin cleansers for acne. Indian Dermatol Venereol Leprol 2015;81:181-5.

39. Seneschal J, Kubica E, Boursault L, et al: Exogeneous inflammatory acne due to combined application of cosmetic and facial rubbing. Dermatology 2012;224:221-3

40. Zorba E, Karpouzis A, Zorbas A, et al: Occupational dermatoses by type of work in Greece. Saf Health Work 2013;4:142-8.

41. Sorg O: Tobacco smoke and chloracne: An old story comes to light. Dermatology 2015;231:297.

42. Hubiche T, Sibaud V: Localized acne induced by radiation therapy. Dermatol Online 2014;20:12.

43. Allen HB, LoPresti P: Acne vulgaris aggravated by sunlight. Cutis 1980;26:2546. 